\title{
Address Forms in Turkish Culture as a Reflection of Social Status
}

\author{
Fatma Tokoz Goktepe \\ Department of English Language Teaching, \\ Cag University, Mersin, Turkey
}

DOI: https://doi.org/10.36941/mjss-2021-0o6o

\begin{abstract}
The study concerned itself with forms of communication and address in Turkish culture and seeks to study how they are today regarding how they have been developed historically. Many variables determine how one addresses another and the reasons behind how that forms are chosen. It is known that what is culturally acceptable and deemed polite varies across many different cultures, although some patterns are identical regardless of the culture in which they are exhibited. For the study, a survey was conducted upon several Turkish individuals, and the findings were analysed to extract specific themes and similarities in answers. The analysis was conducted via the Colaizzi method, in which a seven-step process was used to determine themes and recurring branches of themes in subjective interviews. The findings were reported upon and determined to correlate with what has been reported in previous literature on Turkish culture concerning social norms, forms of address and politeness.
\end{abstract}

Keywords: address forms, Turkish culture, social norm, politeness, Colaizzi method

\section{Introduction}

Throughout human history, cultures have risen and fallen with regularity. Each has been unique in its way, but the main thing that has defined culture is the accepted and understood social norms that all who are a part of the culture choose to adhere to. The social norms can include many things, such as forms of address and terms of politeness, and gestures of deference to those held in high esteem and subconscious slights in attitude towards those who are not held in high esteem. Within the Turkish culture, this is a modern phenomenon and the result of historical background as well. How people in Turkey choose to address each other says a lot about its culture, history, and people. In some ways, Turkish forms of address are unique to the culture, but in other ways, follow a set pattern of social norms that seem to be inherent across all human culture. Some of these social patterns are inborn in human-being throughout history; for example, human beings exhibit certain patterns that all hominids exhibit, like tribal and social species. On the other hand, as an advanced species that develop culture and communication methods beyond what other creatures in nature have developed, so too does a cultural development consciously and progressively, and in some ways, deliberately on the part of those who dwell within it. Thus, certain forms of address and social norms within a culture can change consciously over time as the values of that culture also change.

Analysing address forms in Turkish depicts how Turkish people perceive each other and what aspects may affect their choice of the terms. These terms are also acknowledged as a sign of how 
social and interactional relationships exist among people to analyse whether they have a similar addressing term system in common. Furthermore, address terms in a language play a significant role in transforming the culture (Fitch, 1991; Morford, 1997) and issues like sexuality, age, ethnicity, and religion may also be deduced and realised through these terms (Afful, 2006). However, while some research has been carried out on address forms, there has, to date, been no adequately conducted in Turkish culture focusing on the basis of sociolinguistics functions. Therefore, the problem is a lack of work within this area in Turkish culture that has been significant to motivate sociolinguists in analysing why people speak differently in several contexts. As Holmes (1992) states that "examining the way people use language in different social contexts provides a wealth of information about the way language works, as well as about the social relationships in a community." (p.1)

This paper attempts to address these forms of social norms within Turkish culture by examining the current literature about the forms of social interaction in Turkey, both modern and historical. An examination of the history that rose to certain social norms currently seen in Turkey is also examined. Furthermore, a survey will be conducted on Turkish individuals who answer questions regarding politeness regarding address in their culture. This will be compared to what the literature is known, and the findings will be analysed for accuracy. This paper attempts to address how Turkish social norms with communication have developed and currently stand within modern times and how this pertains to the world of communication in general. Turkish can be a confusing language to those who have not encountered it before. For example, there are two forms of the second-person pronoun "you" /sen/ and /siz/, which can be confusing to the native European language speaker. This pronoun is used dependent upon the setting, the circumstances, and the individual, all of which are culturally based on the determination.

The study considers several aspects and questions Turkish speakers as to what sort of circumstances must exist for them to use a particular form of address for the purpose of politeness and social well-being. From the literature and the findings of this study, we can determine the type of culture that Turkey expresses through its language, contributing heavily to international relations. Modern history is strewn with examples of foreign dealing that goes badly simply because someone offers to shake hands instead of bowing. This can be easily avoided with studies such as these.

\section{Literature Review}

The choice of form of address in Turkish depends on several varying factors, all of which may change the situation's outcome simply by modifying one factor that would make two otherwise identical situations require entirely different forms of address. This is undoubtedly true of many cultures, but we will examine the literature pertaining to Turkish for the purpose of this study. In general, there have been many studies on the use of forms of address for many decades, such as Blum-Kulka's article in 1987, followed by an entire book on the subject of politeness in 1990. (Blum-Kulka, 1990) In these works, the author examines several factors, such as the point that social norms in communication are usually socially agreed upon, regardless of the "official" rules of the language. This is seen in English, in the form of various dialects in which grammatical mistakes are made on purpose for the intent of humour or emphasis on a subject.

In Turkish, the subject of social rank and status comes into play in the forms of address, in which the person of lower status might not be "allowed" to make use of both pronouns of address, while the person of higher rank can use either one at his pleasure. Calvo (1992) points out certain equivalents in the history of the English language with how forms of address were used in Shakespearean times, versus how they are used now, and under what social conditions those forms of address might have been used, following a pattern of linguistic behaviour seen across many types of languages concerning status and rank. Linde (1988) also takes up the study of how patterns of communication, especially with regards to rank, shows up even within a culture's workforce, as some forms of communication in a profession might require the use of language in a particular way that might not be commonly seen in the general population. Although Linde (1988) focuses on the 
aviation profession, another example might be how individuals in the military address varying ranks. How social patterns set the use of language has also discussed by Markel (1990), who pointed out that solidarity in the culture itself determines how forms of address are used, but who also pointed out that when this solidarity begins to break down due to social revolution, likewise the forms of address, especially with regards to rank and social status, can change as well.

Morrison and Conway (2006) also contribute to generalized address patterns seen across human cultures in their book, which follows many different cultures, and what forms of address are different, following specific universal patterns seen globally and historically, regardless of culture geographic location. The Turkish language also conforms to specific patterns of behaviour seen universally in human communication while also adhering to unique characteristics to the language that are primarily due to current culture. Although Kral's (1975) work is a bit dated, many of the subjects spoken about are still relevant today. This included studying how rank and social position determine forms of address in many languages around the world, and that showing deference to those of higher rank is a trait exhibited not just by humans but also by several varying species, who communicate that deference in particular sounds or body language. Nanbakhsh (2011) demonstrated how Turkish, for its unique patterns, was influenced heavily by historical Persian culture, as were many of the Middle East's surrounding cultures still exhibit signs of Persian social norms in communication. Pollard and Pollard (1996) delved more deeply into the Turkish language in their book dedicated to the language, in which many examples of social rank pronouns and forms of polite address are studying and commented upon, many of which follow the universal social patterns endemic to human behaviour in general. How this affects those trying to learn Turkish, or any second language, was studied by Tanaka and Kawade (1982), who pointed out that those attempting to learn a second language naturally attempt to apply the rules of address and word function from their first languages to the second language, often subconsciously, making it difficult for the rules of the second language to sit well in the student's mind, or to be easily retained without practice following the lessons. While sometimes the address rules are similar or follow the universal patterns, sometimes they are very different. Zeyrek (2001) reported upon what makes Turkish unique in forms of address, such as the previous example of the use of different second-person pronouns for the sake of addressing someone of a different social rank, but also how certain rules of universal conversation in Turkish apply to those of all ranks, but differ slightly from other languages and are unique to Turkish. To round up this area of study of the literature, a Turkish language website also outlines some of these similarities and differences, as it is meant to inform travellers to Turkey on the various forms of address for the sake of a foreigner who might be addressing someone to whom they do not understand the rank or the culture of the individual, and how to avoid making a social blunder.

How Turks choose to address each other is a subject concerning many varying factors, some of which follow universal social norms, and some which do not. Baser (2012) conducted a very interesting article in which a study was conducted on English as Second Language Turks who were learning English, which has only one address pronoun, and how they employed it amongst themselves, peers and family members, to determine how students who were typically used to using pronouns to address someone to determine rank were reduced to trying to get the same meaning across using only one pronoun. Bayyurt (1992) also discussed how Turkish students chose forms of address in both the native language and in the second language, and how the Turkish language's use of two pronouns when most languages use one can affect Turkish students. Bayyurt and Bayraktaroglu (2001) later examined the phenomenon of how Turks chose pronoun usage in service professions, in which the server might, socially, be of a higher rank from the individual he is serving, and how social norms might have to change in these service encounters. Understanding these situations involving Turkish and how the language operates, we can now ask the questions of Turkish students who answer upon how they determine pronoun usage when dealing with foreign individuals of whom they might not be certain of rank, how they employ English which uses only one pronoun, and how their culture contributes to this phenomenon.

Wardhaugh (2006) examines second-person pronouns of 'formal' and 'familiar' forms that many 
languages have tu-vous (T/V) distinction in French, which refers to the singular/familiar 'tu' and plural/formal 'vous' of French along with other examples such as the Russian 'ty'/'vy', German 'du'/'Sie', and Italian 'tu'/'Lei'. He describes how solidarity concepts, especially with lower-class, came to be identified by symmetrical $\mathrm{T}$ usage, while asymmetrical $\mathrm{T} / \mathrm{V}$ usage symbolised class/power relationship and upper-class privilege. According to Brown and Gilman (1960, cited in Wardhaugh, 2006, p.260), several uses of address forms point out intimacy, formality or inequality. Titles usually signal ranks or professions, whereas using the first name suggests intimacy and using a nickname marks a greater intimacy.

\section{Methodology}

\subsection{Data Collection and Participants}

The participants in this study were thirty native Turkish individuals who speak Turkish as a first language. Both males and females were asked to participate. Data were collected through a questionnaire to determine the address forms used while addressing a person and the situations where we used these address forms.

The questionnaire consisted of ten questions concerning Turkish culture's address forms regarding rank, specific circumstances, and general questions concerning rudeness and politeness in Turkish culture.

\subsection{Data Analysis}

Due to the subjective nature of the responses concerning politeness and forms of address in Turkish culture, it is necessary to use the Colaizzi method to extract valuable data from the analysis responses. Firstly, the data was recorded via some form of a recording medium and arranged for easy retrieval. Secondly, any statements that were deemed significant were highlighted and noted. Next, the meaning of those statements was assigned concerning how the researcher believes the statement was intended. Next, those meanings were arranged into any prominent recurring themes. Following that, those themes were defined in the mind of the researcher. Next, the researcher describes, using those themes, how they relate to the entire situation being studied as a whole. Finally, in an accurate Colaizzi analysis, the final step would be to ask the participants to review the data to ensure that the overall findings and analysis of their responses does indeed reflect their intended meaning in their answers, to verify the accuracy of the researcher's interpretations (Shosha, 2012).

\section{Findings}

The survey findings administered to the test subjects showed a variation of opinions across the board with a concern of address in Turkish culture; however, many similarities were also noted. Initially, the respondents were divided somewhat unequally amongst males and females, with more males participating than females, and given that the subjects understood English well enough to communicate via a survey taken in English, it is assumed that most of the respondents are also college-educated, although this information was not collected via the survey. It is unfortunate that a few of the respondents only took the survey for the purpose of being glib and unserious, which necessitated the removal of their answers as part of the data collection overall. Some of the answers given in two different questions were similar in nature, although elaboration was usually employed in the latter question, which was also considered in the analysis phase.

Among males and females, all responded that men tended to communicate more directly, while women were less direct. Men typically used each other's given names when addressing each other, while men were more likely to employ terms of endearment or nicknames when addressing women. Men were also more likely to use more slang with each other. Both males and females reported that 
the level of acquaintance determined the difference of address when addressing someone of the same or opposite gender, and older individuals automatically commanded more respect in address. The use of the term "beyefendi" was more formal and might be used with a not well-known male acquaintance. The term "hanımefendi" would be used with females. Males who are well-known to each other might be addressed as "amca," while females well-known to each other would be addressed by "teyze." How one addresses someone of lower status that himself is also determined by the degree of familiarity, as those who are younger are often addressed by their first name. If the individual is older than the person, they might be addressed as "abla," "Abi", or "siz."

When addressing an individual of equal status to oneself, most respondents reported that the first name is used if the individual is close to you. If the individual is family, then the term "canım" is used. A more formal address would be the use of the terms "hanım," "bey", or "sen." These terms are also used if the individual has a higher social status of oneself. Of course, many social encounters might cause some of these cultural norms to be tested or disregarded, such as when a person is working as a waiter or some other service profession and must attend to someone of a lower social rank than himself. In this case, it is most common to stick to a formal address, regardless of who is being addressed, using the term "siz," which expresses the distance between the server and the person or shows a social standing distance overall.

When dealing with non-Turkish individuals or foreigners in general, it is more common to use the individual's first name, depending on the encounter's interaction and context. Foreigners are often given a wider berth with terms of address, and for the sake of friendliness and camaraderie, the use of the first name is often employed, especially when one does not know the foreigner's social status to whom he is addressing. Of course, as with many interactions between people of different cultures, there is also the possibility of inadvertently offending due to a violation of social norms. In Turkish culture, this could happen if the foreigner makes fun of Turkish religion or traditions or offers alcohol to a Turk without first determining whether or not the Turkish individual drinks alcohol, which can occasionally be prohibited by religion. If a foreign individual uses the term "sen," which is more familiar term, and denotes an equal or higher standing, rather than the use of the term "siz", which denotes a more distance between the individuals or lower ranking, then it can inadvertently offend the Turk.

When questioned about the varied ways in which an individual can be both polite and rude, the Turkish correspondents reported that politeness is usually denoted by being thankful for actions that are done for you and for being welcoming and friendly, which can involve sharing food. It is also considered polite to stand up when somebody of a higher social rank enters the room. Various types of rude behaviour described regarding Turkish culture include being disrespectful of those in the service industry or using various types of body language when saying no to somebody. Showing prejudice based on religion is also considered rude, as are the violations of specific traffic laws and the lack of consideration. Finally, it is considered extremely rude to shout at an older person, such as parents or professors, as raising a voice in itself is considered extremely rude in Turkish culture. For this reason, it is also considered rude to smoke in front of one's father.

\section{Discussion}

Upon using the Colaizzi method to identify various themes and lines of thought in the subject of answers given by the respondents to the survey, we begin to see a running theme in the answers given by the respondents, with regards to communication and the various forms in which address can be chosen. The primary theme seems to be the social rank and familiarity with which the two communicators have. There does not seem to be a marked difference with how the genders communicate, but rather how social status determines the level of regular communication, regardless of gender. Both men and women are addressed with the same pronoun if they look to inhabit the same social rank regarding the individual in question, and if the social rank is unknown than a certain level of formality is assumed. It should be noted that the respondents are all of college-age 
and thus find themselves frequently addressing their parents and professors with formality while maintaining a certain degree of relaxation amongst their peers, who are their equals. In this case, the use of an informal address is much more common.

It is also worth noting the varying degrees to which males responded on how they address their female counterparts. Without being able to determine the motivation of the males in question for using endearments over formal names, it would seem that the use of nicknames and endearments as a form of informal address amongst their social peers would indicate the lack of assumption that the female, in general, is equal to the male, and thus not likely to be addressed by the first name over a term of endearment. This could be in part due to the fact that the Turkish culture is predominantly patriarchal, as are the majority of religions practised in Turkey. While it might not necessarily be conscious that the male considers the female his inferior, if the male respondents are correct in their answers, it seems that this is the case subconsciously, if not consciously. However, it is important not to make too many assumptions about this use of address, especially when viewing the data through the lens of one's own culture, which might differ from the Turkish culture. It is also worth noting that the researcher administering the survey was female, and the respondents who chose to act in a glib manner with their answers were male, which could also indicate a lack of seriousness regarding the research being conducted by a female. However, this is impossible to know for sure without further study of the test subjects.

Many of the respondents indicated that they would not change the way they address individuals, should role reversals due to employment in service industries, cause a situation in which they might find themselves subservient to someone of a lower social rank. All respondents indicated that they would err on the side of caution and address the individual in a distant but formal manner. This is likely the case in many different cultures; assuming that an individual is of lower rank than you are often an erroneous one and could cause social interactions problems. The use of the more formal and yet distant term "siz," while more commonly used amongst those of a lower social rank, is also politely distant. This also seems to be the case when addressing individuals who are younger than oneself, which automatically denotes them to a lower rank.

As to how a foreigner might be addressed or might inadvertently cause offence, many of the respondents followed a similar theme: rudeness from a foreigner would be perceived due to a lack of understanding of religious culture. Due to uncertainty about foreigners' social rank, many Turkish individuals choose to remain polite, but the distance in addressing them, unless the individual is of the same age, at which point the first name is often used. Foreigners might be given a wide berth using pronouns misused due to social rank, but the universal offence that could because by a foreigner would be disrespect for religion or culture overall. Of course, this is also the case in many other cultures, for it is unwise for the tourist to visit a culture only to make fun of it within earshot of the locals. It might be prudent for individuals travelling to Turkey to become aware of what is considered rude and make a conscious effort to avoid the scenario, especially when addressing Turkish individuals.

Finally, it is also worth noting in the findings that behaviour that is considered polite is more or less universal to this area of the world and parts of Europe and Africa. This includes being open and friendly with those you meet and showing consideration for others, both in traffic and business dealings. The sharing of food is a universal means of welcoming and politeness as well. Turkish culture also seems that respect for elders, such as parents, professors, and grandparents, is also a uniform politeness method, including not raising one's voice to those older than himself.

Several implications can be drawn from this research and findings. One is that the Turkish culture is not so different from any other cultures regarding politeness and rudeness, and social rank. For the foreigner travelling to Turkey, it is best to assume that he automatically inhabits a lower social rank and treats all individuals with politeness and generosity and deference, especially older individuals. It is also worth the tourist understanding certain forms of address in Turkish culture and avoiding using the incorrect one when interacting with Turkish individuals. Whether or not the Turkish culture itself is evolving regarding the addressing of individuals due to social rank, this can 
be subject to discussion in future surveys that could be administered. Many cultures worldwide are changing with the Internet's interconnectivity and the exchange of cultural ideals overall.

The findings of this study have many implications regarding the study of social interactions and cultural studies. It is known that social norms within a culture can change over time for a more permanent fixture or rapidly in a short time due to a fad or movement within the culture. The use of slang, for example, is often generational, with the slang dying out over a few decades, with only a few words from the slang culture remaining in the vernacular permanently. Likewise, social interactions might change from social movements within a society, and the use of endearments towards women amongst college-age men might change to something more formal should a shift in attitudes towards women's equality become more prevalent in the society over time. Studies such as this one would help identify those short-term trends and long-term trends in any society that might contribute to the overall understanding of the society in question both presently and historically.

However, it would also be prudent to mention the limitations of this study and how these limitations might affect the data's overall outcome. To begin with, the sample size would do well from an increase in numbers, and securing the participation of willing participants prior to the study itself would be preferable in future studies. Survey Monkey's use to collect data is extremely useful, especially given the analysis tools at the researcher's disposal via the website. However, it is not easy to control how the survey is taken when conducted anonymously over the Internet. It remains to be taken on the honour code that the respondents are indeed presenting themselves truthfully as either males or females of certain social rank, or indeed that they are Turkish at all. It is also impossible to utilize a critical aspect of the Colaizzi method of analysis, which includes asking the respondents to verify their answers after the findings have been reached to determine if the meaning gleaned by the researcher was the intended meaning of the respondent. As the survey was taken anonymously, the respondents could not conduct the verification procedure after reaching the findings. This leaves the door open for the possibility that the collected data were misapprehended, thus rendering the findings somewhat less than credible. In the future, such surveys would be better to be done in person if possible.

This would allow the researcher some modicum of control over the testing environment, the behaviour of the respondents, and the truthfulness of the demographic data that would be collected. It is also likely that informal interviews, in concert with the surveys, should be conducted during the information gathering phase, that would allow the researcher to clarify before analysis any unclear meanings or duplication of answers that might skew the findings in such a way as to render them useless in the analysis stage.

\section{Conclusion}

In conclusion, we can see that terms of address in Turkey are often determined by a level of familiarity and social rank amongst individuals. Centuries of customs have put into place the formalities used in Turkish society that still apply to modern times. Turkey itself is at a crossroads between the East and West, and the culture bears the hallmarks of the influence of many types of cultures converging in this one location while remaining unique unto itself. What has been considered cultural norms have changed dramatically over time with regards to which outside influences have dominated the culture at the time, which later became part of overall modern Turkish culture? This might change society today with the acceptance of changing gender roles, and the changing of incoming ideas and values from outside Turkey remains to be seen. Many countries have experienced social upheaval in the last century, which completely rewrote the terms of interaction and respect amongst individuals within the society. It may be that Turkey could be experiencing a smaller one from within just as other countries are experiencing. Often, the young adult generation drives such social change, often by disregarding their elders' social norms when interacting with each other, while maintaining or sometimes the established social norms of their society with their elders. Eventually, the younger generation's changes become part of society, and 
Turkey's experiences would differ. As we have seen in this study, some aspects of politeness are universal, and they never completely die out, such as respect for elders, which is doubtful any change in social standings would ever alter. However, how the younger generation interacts amongst themselves as adults and those outside of Turkey, especially regarding interactions on the Internet, remains to be seen. It is possible that, in the near future, if not already, interactions on the Internet will form its society, and this could carry over into other societies to become part of a global community with its social norms, terms of address, and standards of interaction.

\section{References}

Afful, J. B. A. (2006). Address terms among university students in Ghana: A case Study. Journal of Language and Intercultural Communication 6(1), 76-91.

Baser, B. (2012). A comparison of the address forms used in the family between Turks and Americans. (Unpublished MA thesis). The University of Vienna, Austria.

Bayyurt, Y. (1992). The analysis of the determining factors affecting people's choice of address forms in Turkish. (Unpublished MA Thesis). Department of Linguistics and English Language, Lancaster University, UK.

Bayyurt, Y., \& Bayraktaroğlu, A. (2001). The use of pronouns and terms of address in Turkish service encounters. In A. Bayraktaroğlu \& M. Sifianou (Eds.), Linguistic politeness across boundaries. The case of Greek and Turkish (pp. 209-240). Amsterdam: John Benjamins.

Blum-Kulka, S. (1987). Indirectness and politeness in requests: same or different?. Journal of pragmatics, 11(2), pp.131-146.

Blum-Kulka, S. (1990). Politeness (1st ed). Amsterdam: North-Holland.

Calvo, C. (1992). Pronouns of address and social negotiation in as you like it. Language and Literature, 1(1), 5-27.

Fitch, K. L. (1991). The interplay of linguistic universals and cultural knowledge in personal address: Columbian Madre terms. Communication Monographs, 58, 254-272.

Holmes, J. (1992). An introduction to sociolinguistics. London: Longman.

Kral, T. (1975). Sociolinguistic patterns in Turkish address (1st ed). Ann Arbor, Mich.: Xerox University Microfilm.

Linde, C. (1988). The quantitative study of communicative success: Politeness and accidents in aviation discourse. Language in Society, 17(3), 375-399.

Markel, N. (1990). Speaking style as an expression of solidarity: Words per pause. Language in Society, 19(1), 81-88.

Morford, J. (1997). Social indexicality in French pronominal address. Journal of Linguistic Anthropology, 7, 337.

Morrison, T. \& Conaway, W. (2006). Kiss, bow, or shake hands (1st ed.) Avon, Mass: Adams Media.

Nanbakhsh, G. (2011). Persian address pronouns and politeness in interaction. Edinburgh: University of Edinburgh.

Pollard, A. \& Pollard, D. (1996). Turkish (1st ed). Lincolnwood (Chicago), Ill. NTC Pub. Group.

Shosha, G. (2012). Employment of Colaizzi's strategy in descriptive phenomenology: A reflection of a researcher. European Scientific Journal, 8(27).

Tanaka, S. \& Kawade, S. (1982). Politeness strategies and second language acquisition. Studies in Second Language Acquisition, 5(01), 18-33.

Wardhaugh, R. (2006). An introduction to sociolinguistics (5th Ed.). Blackwell Publishing: Australia

Zeyrek, D. (2001). Politeness in Turkish and its linguistic manifestations. Linguistic Politeness across Boundaries. The Case of Greek and Turkish Amsterdam: Benjamin's Publ. Co. 43-73. 